\title{
The Relationship between Emotional Intelligence and Teaching Effectiveness among Lecturers at Universiti Teknologi MARA, Puncak Alam, Malaysia
}

\author{
Narehan Hassan, Syahrina Hayati Md. Jani, Rohana Mat Som, Nur Zainie Abd Hamid, and Nor \\ Azmaniza Azizam
}

\begin{abstract}
In this study, the researchers examined the relationship between emotional intelligence (EI) and teaching effectiveness among lecturers at Universiti Teknologi MARA (UiTM), Puncak Alam, Selangor. The participants consisted of 155 lecturers working at UiTM, Puncak Alam, Selangor. The respondents were randomly selected and the data were gathered through the distribution of questionnaires. Descriptive statistics showed that there were more female than male faculty members and majority of them were from the Faculty of Office Management and Technology. The study found that there was a positive and significant relationship between overall EI skills and overall teaching effectiveness. Lecturers with high EI were found to have high self-confidence and were more committed towards their job. In conclusion, the lecturers needed to learn, master and practice EI skills in identifying their strengths, and weaknesses in order to maximize teacher-student interaction.
\end{abstract}

Index Terms-Education, effective teaching, emotional intelligence (EI), lecturers, teaching effectiveness.

\section{INTRODUCTION}

In Malaysia, both public and private higher education institutions are growing rapidly to accomplish the increasing demands from stakeholders in preparing graduates with the knowledge, skills and abilities needed, and to ensure that graduates are successful in the workplace. As a result, the number of lecturers in universities has been increasing over the years, parallel with the increasing numbers of higher education institutions [1].

In the academia, the quality of teaching is related to teaching effectiveness [2]. However, the environment of local universities is very challenging due to the increasing demands, standards, and expectations of the public, stakeholders and the Ministry of Higher Education. The lecturers are overwhelmed with multiple roles and tasks such as conducting research for promotion purposes, attending seminars, project presentations and engaging in students' and community service activities [3]. Subsequently, the lecturers have the tendency to experience negative emotions such as tension, hostility, depression, anger, nervousness and frustration [4].

Therefore, it is vital for lecturers not only to possess the appropriate knowledge, skills and abilities to ensure the optimum transfer of knowledge, but to equip themselves with

Manuscript received September 25, 2013; revised November 28, 2013.

The authors are with the Faculty of Business Management, Universiti Teknologi MARA, Malaysia (e-mail: narehanhassan@gmail.com). another pertinent aspect of teaching called the emotional intelligence.

\section{LITERATURE REVIEW}

\section{A. Dimension of Emotional Intelligence}

The dimensions of EI used were according to the Emotional Skills Assessment Process (ESAP), which involved interpersonal skills, personal leadership skills, self-management skills, and intrapersonal skills [5].

\section{B. Interpersonal Skills}

According to [6], "interpersonal skills are at the heart of teaching". This is because lecturers are expected to interact effectively with different people, able to communicate with students, peers, parents, administrators, and other professional personnel [6]. Additionally, [7] stated that excellent lecturers creating learning interest through linkage between knowledge and its application and communicating with students actively. Interpersonal skills are necessary because it is where the decision-making is shared and trust is built through collaborative working relationships [6]. [3] stated that in order to be a lecturer, interpersonal skills are the basic skills required. Without the skills, lecturers will not able to achieve effective teaching.

\section{Personal Leadership Skills}

Studies conducted revealed the understanding on the importance of emotional intelligence skills on the success of individuals, groups as well as organizations to become effective leaders [8]. Effective lecturers need to possess leadership competencies to work well in their tasks and among staff, peers, students, or the community [9].

Lecturers can be effective leaders in the classroom or as peers. According to [10], there are five important points for lecturers with effective leadership. The five points for lecturers with effective leadership include realize and honor students' interests, passionately teach students with the knowledge, skills and strategies that they need to succeed, build on students' unique strengths, unleash the strengths, talents and passions of students and listen to the hopes of students [10].

According to [5], social awareness (comfort), empathy, decision-making and leadership are important components in the dimension of personal leadership skills. Social awareness skills allow a person to promptly establish and comfortably maintain effective interpersonal relationships with individuals and groups [5]. Furthermore, lecturers with the 
empathy skills can exactly understand and accept various viewpoints of students and that empathy exists in acceptance, trust, caring and respectful relationships [5]. Other than that, empathy helps lecturers to notice the nonverbal actions of students, thus make appropriate adjustments to dispel their doubts and fears [9].

\section{Self-Management Skills}

In today's competitive environment, the role of higher education institutions has become more challenging. Due to that reason, the profession as a lecturer has also become more difficult together with teaching and research responsibility. The effectiveness of self-management is vital to achieve higher levels of academic and career success for lecturers. Self-management skills enhance individual's ability to assess problems, set challenging goals related to problems, as well as distinguish and manage elements that reinforce and deter goals achievement [9]. [5] reported that self-management consisted of drive strength, commitment ethic and time management.

\section{E. Intrapersonal Skills}

As stated in Emotional Skills Assessment Process (ESAP), the intrapersonal skills include self-esteem and stress management [5]. [5] defined self-esteem as the learned ability of confidence to achieve individual meaningful goals whereas; stress management is the learned ability to manage stress, pressure and anxiety in life and work.

Ref. [11] stated that the ability to handle stress and manage feelings is another part of EI, crucial for success. [5] also reported that negative self-judgments and self-rejections are related to self-destructive and self-defeating behaviors, while positive self-esteem is essential to people's internal motivation and external behavior. Further, [12] also reiterated that teaching is a stressful career and highlighted that, high levels of negative stress and emotional reactivity can lead to burnout. This fact is also supported by [13] who stated that an occupation with high emotional demand and frequent stressful activity is teaching.

Ref. [14] conducted a study among 158 freshmen to examine the relationship between EI (emotion-relevant abilities) and stress (feelings of inability to control life events), and considering personality (self-perception of the meta-emotion traits of clarity, intensity, and attention) as a moderating variable. Outcome from the study shows that EI is probably practical in reducing stress for some people, but unnecessary or not relevant for others [14].

\section{F. Definition of Teaching Effectiveness}

Ref. [15] defined effective teaching as the process of making student learning possible, promote engagement and discussion, concern and respect for students and maximizing students' academic achievement. [16] defined teaching effectiveness as "the extent to which the teaching activity fulfils its intended purpose, function and goals".

\section{G. Analytical Approach}

Ref. [17] summarized the characteristics associated with effective lecturers. The characteristics are confidence, trustworthiness, commitment, respect, analytical thinking, conceptual thinking, drive for improvement, information seeking, initiative, flexibility, accountability and passion for learning [17]. In addition, [18] stated that a good lecturer plays the roles as a facilitator, assessor, participant and motivator to promote student participation and provide update information.

Ref. [15] stated that the lecturer should present facts and concepts from related fields, discuss point of view of students as well as present origins of ideas and concepts. This is because the students associate knowledgeable faculty members to effective teaching and expect the lecturers to possess the ability to communicate freely about their subject area [19].

\section{H. Clarity of Teaching}

Ref. [9] stated that “... students perceived best-liked teacher attributes as organized and prepared, knowledgeable, able to communicate, cared about students, enthusiastic about subject and challenging and demanding, whereas least-liked teacher attributes comprised of uninteresting, unprepared, unclear, bad attitude and disorganized." [20] stated that the lecturers who are willing to share their knowledge are absolutely will be stepping towards the effective classroom. [20] further stated that the key factor that provides a foundation for a good teaching is teacher knowledge. According to [19], the students want their lecturer to talk to them in a meaningful way, their notes are well organized and the visuals are used for clarification. It is vital for the lecturers to explain clearly, well prepared, summarize major points and state objectives for each class session [15].

However, the lecturers should be honest if they do not know the content clearly. The students are ready to accept lecturers who are honest about not knowing the answer to a question but are willing to seek out the answer and bring it back to class [19]. Furthermore, the effective lecturers are able to maximize the instructional time, avoiding irrelevant materials, providing lists of supplementary course materials and giving tutorials [19].

\section{Lecturer-Group Interaction}

The Seven Principles for Good Practice in Undergraduate Education by [21] formulated a set of guiding principle to improve teaching. The principles include good practices, which encourage student-faculty contact, cooperation among students, active learning, gives prompt feedback, emphasizes time on task, communicates high expectations and respects diverse talents and ways of learning [22]. [15] found that a lecturer needed to encourage their students to give their opinions as well as sharing their knowledge and experiences in the class.

Besides, it is also important for the lecturer to give and invite constructive criticisms to encourage student learning and provide experiences that could increase self-confidence [19]. Furthermore, effective lecturers should be really concern about the quality of their teaching and are able to identify whether the students understood the lessons not [15].

\section{J. Lecturer-Individual Student Interaction}

Lecturers' characteristics are vital to the development of a positive relationship between student and lecturer. Lecturers should respect student as a person and be friendly [15]. According to [23], lecturers' characteristics could help in encouraging positive academic and behavioral student outcomes such as assisting positive influence towards students, creating talent and the ability to provide positive 
feedback.

It is also necessary for the lecturers to be accessible to the students out of class to accomplish the objectives of the institution [24]. As stated by [19], effective lecturers should have a sense of respect for their students. This is because the students are more likely to appreciate lecturers who are compassionate and understanding, treat them with respect and make them feel comfortable to ask questions [19].

\section{K. Enthusiasm of Lecturer}

Ref. [23] claimed that lecturers who are unmotivated and apathetic towards their subject are likely to have worse educational outcomes than lecturers who are excited and enthusiastic about their subject matter. [15] also reported that students prefer their lecturers to have interesting style of presenting their lectures.

\section{RESEARCH OBJECTIVES}

To identify the relationship between EI and teaching effectiveness among lecturers at Universiti Teknologi MARA (UiTM), Puncak Alam, Selangor.

\section{RESEARCH HYPOTHESES}

$H_{1}$ : There is a significant relationship between EI skills and teaching effectiveness.

$H_{l a}$ : There is a significant relationship between interpersonal skills and teaching effectiveness.

$H_{l b}$ : There is a significant relationship between personal leadership skills and teaching effectiveness.

$H_{l c}$ : There is a significant relationship between self-management skills and teaching effectiveness.

$H_{l d}$ : There is a significant relationship between intrapersonal skills and teaching effectiveness.

\section{RESEARCH METHODOLOGY}

\section{A. Research Design}

The study used a quantitative research method to identify the correlations between emotional intelligence skills and teaching effectiveness.

\section{B. Study Participants}

The total population comprised of 258 lecturers from these faculties. Table I shows the population and sample of lecturers. The population was randomly ordered and systematic sampling technique was adopted to ensure unbiased sample (Zou, 2006). [26] Table was used to determine the most appropriate sample size. It was determined that from the population of 258, the desired sample was 155 . The response rate was $64.5 \%$.

TABLE I: POPULATION, SAMPLE SIZE AND RESPONSE RATE

\begin{tabular}{lcccc}
\hline \hline Faculties & Population & Sample & $\begin{array}{c}\text { No. of } \\
\text { Lecturers }\end{array}$ & $\begin{array}{c}\text { Response } \\
\text { Rate (\%) }\end{array}$ \\
\hline $\begin{array}{l}\text { Health Sciences } \\
\text { Office Mgt. \& }\end{array}$ & 109 & 75 & 43 & 27.7 \\
Technology & 84 & 50 & 44 & 28.4 \\
Pharmacy & 65 & 30 & 13 & 8.38 \\
Total & 258 & 155 & 100 & 64.5 \\
\hline \hline
\end{tabular}

\section{Measurement}

The elements used for measurement were the Emotional Skills Assessment Process (ESAP), which consisted of interpersonal skills, personal leadership skills, self-management skills and intrapersonal skills. Therefore, the characteristics of emotional intelligence skills involve in this study were assertiveness, decision making, leadership, time management, commitment ethic, self-esteem and stress management. Table II shows in detail each of the areas and sub-areas in ESAP.

The interpretation of EI skills scores was based on Best's principles (Thaoprom, 2004) where the maximum-minimum scores were divided by three ranges of high, medium and low that is, $5-1 / 3=1.33$. Therefore, the results are as follow:

- Scores 1.00 to $2.33=$ Low EI skills

- Scores 2.34 to $3.67=$ Medium EI skills

- Scores 3.68 to $5.00=$ High EI skills

TABLE II: THE DIMENSIONS AND CHARACTERISTICS OF EI SKILLS

\begin{tabular}{llc}
\hline \multicolumn{2}{c}{ Skills and Characteristics } & No. of Items \\
\hline Interpersonal & Assertiveness & 4 \\
\multirow{2}{*}{ Personal Leadership } & Decision-Making & 4 \\
& Leadership & 4 \\
Self-Management & Time management & 4 \\
& Commitment Ethic & 4 \\
Intrapersonal & Self-Esteem & 4 \\
& Stress Management & 4 \\
\hline \hline
\end{tabular}

The measurement for teaching effectiveness was conducted using the Student Evaluation of Teaching Effectiveness (SETE). The original SETE had five elements such as analytical approach, clarity of teaching, lecturer-group interaction, lecturer-individual student interaction and enthusiasm of lecturer [15].

Subsequently, the SETE comprised of 35 critical elements. Since the number of elements was relatively excessive, the researchers decided to reduce the elements to 20 elements by looking at the highest rank of each of the five elements. The highest rank indicated very important, whereas the lowest rank indicated not important at all. Overall, the questions were reduced as illustrated in Table III.

TABLE III: ELEMENTS OF TEACHING EFFECTIVENESS

\begin{tabular}{lc}
\hline \multicolumn{1}{c}{ Elements } & No. of Items \\
\hline Analytical Approach & 4 \\
Clarity of Teaching & 4 \\
Lecturer-Group Interaction & 4 \\
Lecturer-Individual Student Interaction & 4 \\
Enthusiasm of Lecturer & 4 \\
\hline \hline
\end{tabular}

Table IV shows the reliability statistic for both EI skills and teaching effectiveness. Cronbach's alpha for EI comprised of interpersonal, personal leadership, self-management, and intrapersonal in the range of 0.821 . Meanwhile, the Cronbach's Alpha for teaching effectiveness in the range of 0.882 . Therefore, the result indicated that the measures have high internal consistency. 
TABLE IV: CRONBACH'S ALPHA SCORES FOR OVERALL EI, EACH DIMENSION OF EI AND TEACHING EFFECTIVENESS $(N=100)$

\begin{tabular}{lcc}
\hline \hline \multicolumn{1}{c}{ Scales } & $\begin{array}{c}\text { No. of } \\
\text { Scale Items }\end{array}$ & $\begin{array}{c}\text { Reliability } \\
\text { Coefficient (Alpha) } \\
(n=100)\end{array}$ \\
\hline Interpersonal Skills & 4 & 0.505 \\
Personal Leadership Skills & 8 & 0.762 \\
Self-Management Skills & 8 & 0.788 \\
Intrapersonal Skills & 8 & 0.707 \\
Overall EI & 28 & 0.807 \\
Teaching Effectiveness & 20 & 0.927 \\
\hline \hline
\end{tabular}

\section{FINDINGS}

Five research hypotheses were formulated to answer the research question as displayed in Table V. Pearson product-moment correlation coefficients were computed between the dimensions of EI and the overall teaching effectiveness.

TABLE V: SUMMARY OF THE RESULT FOR RESEARCH QUESTION ONE

\begin{tabular}{l} 
Research Question and Hypotheses \\
\hline What is the relationship between EI skills and \\
teaching effectiveness among lecturers at \\
Universiti Teknologi MARA (UiTM) Malaysia, \\
Puncak Alam, Selangor?
\end{tabular}

$\mathrm{H}_{1}$ : There is a significant relationship between emotional intelligence skills and teaching effectiveness.

Positive, large and significant relationship $(r=0.620, p<0.01)$

$\mathrm{H}_{1 \mathrm{a}}$ : There is a significant relationship between overall interpersonal skills and overall teaching effectiveness.

Positive, small and significant relationship $(r=0.257, p<0.01)$

Positive, medium and significant relationship $(r=0.477, p<0.01)$

1b: There is a significant relationship between overall personal leadership skills and overall teaching effectiveness.

Positive, large and significant relationship $(r=0.595, p<0.01)$ overall self-management skills and overall teaching effectiveness.

Positive, medium and significant relationship

$(r=0.329, p<0.01)$

$\mathrm{H}_{1 \mathrm{~d}}:$ There is a significant relationship between overall intrapersonal skills and overall teaching effectiveness.

\section{CONCLUSIONS}

The research question for this study was what is the relationship between EI skills and teaching effectiveness? Overall, the findings of the study supported all hypotheses.

In conclusion, the lecturers who achieved overall EI skills were found to score high on teaching effectiveness. [3] suggested that EI skills play an important role in teaching effectiveness and increase job performance of the lecturers. By acquiring EI, lecturers will undoubtedly enhance job performance as well as organizational performance, academic achievement and personal career excellence ([4], [9], [13], [27]). In addition, EI helps lecturers to communicate clearly, lead others, and build great relationship at work and personal life [5]. Therefore, lecturers who successfully develop emotional skills and form emotionally intelligent behavior on a daily basis experience greater success and satisfaction in their professional career and life [12].

\section{REFERENCES}

[1] K. H. Mok, "The rise of transnational higher education in Asia: Student mobility and studying experiences in Singapore and Malaysia," Higher Education Policy, vol. 25, no. 2, pp. 225-241, 2012.

[2] C. R. Emery, T. R. Kramer, and R. G. Tian, "Return to academic standards: A critique of students evaluations of teaching effectiveness," Quality Assurance in Education, vol. 11, no. 1, pp. 37-46, 2013.

[3] I. Iskandar, R. M. Majzub, and Z. Mahmud, "Kecerdasan emosi dan komitmen pekerjaan dalam kalangan pensyarah universiti di Indonesia (Emotional quotient and work commitment among lecturers at an Indonesian university," Journal Pendidikan (UKM), vol. 34, no. 1, pp. 173-186, 2009.

[4] A. Ismail, Y. S. Suh, M. N. E. Ajis, and N. F. Dollah, "Relationship between occupational stress, emotional intelligence and job performance: An Empirical study in Malaysia," Theoretical and Applied Economics, vol. 10, no. 539, pp. 3-16, 2009.

[5] D. B. Nelson and G. R. Low, Emotional Intelligence: Achieving Academic and Career Excellence, $2^{\text {nd }}$ ed. New York: Prentice Hall, 2003, pp. 9-13.

[6] Teacher Education Handbook, West Virginia University Parkersburg, 2009 , pp. 2.

[7] H. Lee and E. B. Yang, "A study on the characteristics of excellent lecturers in medical school," Korean Journal of Medical Education, vol. 25, no. 1, pp. 47-53, 2013.

[8] H. V. Tang, M. S. Yin, and D. B. Nelson, "The relationship between emotional intelligence and leadership practices: A cross-cultural study of academic leaders in Taiwan and the USA," Journal of Managerial Psychology, vol. 25, no. 8, pp. 899-926, 2009.

[9] F. F. Hwang, "The relationship between emotional intelligence and teaching effectiveness," Ph.D. dissertation, Texas A\&M University Kingsville, United States, 2007.

[10] R. F. Bowman, "Teacher as servant leader," The Clearing House, vol. 78, no. 6, pp. 257-259, July 2005.

[11] C. Cherniss, "Emotional intelligence: What it is and why it matters," presented at the Annual Meeting of the Society for Industrial and Organizational, New Orleans, LA, 2000.

[12] D. B. Nelson, G. R. Low, and P. D. K. Nelson, "The emotionally intelligent teacher: A transformative learning model," Manuscript. Retrieved on December, Unpublished, vol. 7, 2012.

[13] B. Ogrenir, "Investigating the relationship between emotional intelligence and pre-service teachers' views of teacher effectiveness,' Ph.D. dissertation, The Pennsylvania State University, United States, 2008.

[14] C. L. Gohm, G. C. Corser, and D. J. Dalsky, "Emotional intelligence under stress: Useful, unnecessary, or irrelevant?" Personality and Individual Differences, vol. 39, pp. 1017-1028, 2005.

[15] O. Aregbeyen, "Students' perceptions of effective teaching and effective lecturer characteristics at the University of Ibadan, Nigeria," Pakistan Journal of Social Sciences, vol. 7, no. 2, pp. 62-69, 2010.

[16] L. Jahangiri, T. W. Mucciolo, M. Choi, and A. I. Spielman, "Assessment of teaching effectiveness in U.S. Dental schools and the value of triangulation," Journal of Dental Education, vol. 72, no. 6, pp. 707-718, 2008.

[17] L. W. Anderson, Increasing Teacher Effectiveness, Paris, UNESCO: International Institute for Educational Planning, 2004, pp. 21.

[18] C. Y. Chen, P. Sok, and K. Sok, "Benchmarking potential factors leading to education quality: A study of Cambodian higher education," Quality Assurance in Education, vol. 15, no. 2, pp. 128-148, 2007.

[19] J. Delaney, A. N. Johnson, T. D. Johnson, and D. L. Treslan, Students' Perceptions of Effective Teaching in Higher Education, Memorial University of Newfoundland, Distance Education and Learning Technologies, 2010.

[20] P. Gurney, "Five factors of effective teaching," New Zealand Journal of Teachers' Work, vol. 4, no. 2, pp. 89-98, 2007.

[21] A. W. Chickering and Z. Gamson, "Seven principles for good practice in higher education," American Association of Higher Education Bulletin, vol. 39, no. 7, pp. 3-7, 1987 
[22] D. Padavano and M. Gould. (2004). Best practices for faculty who teach. online. Deonews. [Online]. 13(9). pp. 1-14. Available: http://www.ed.psu.edu/acsde/deos/deosnews/deosnews13_9.pdf

[23] C. A. Robitaille, "Emotional intelligence and teachers: An exploratory study of differences between general and special education teachers," $\mathrm{Ph} . \mathrm{D}$. dissertation, Union Institute and University, United States-Ohio, 2008.

[24] H. T. Ekundayo, P. E. Konwea, and M. A. Yusuf, "Towards effective time management among lecturers in Nigerian Universities," Journal of Emerging Trends in Educational Research and Policy Studies, vol. 1 no. 1 , pp. 22-24, 2010

[25] J. Zou. (2006). Elements of statistics. [Online]. Available: http://www.ams.sunysb.edu/
[26] R. V. Krejcie and D. W. Morgan, "Determining sample size for research activities," Educational and Psychological Measurement, vol. 30, pp. 607-610, 1970

[27] P. C. Hall, "Potential predictors of student teaching performance: Considering emotional intelligence," Ph.D. dissertation, Dept. of Teaching and Learning, University of Utah, Salt Lake City, Utah, United States, 2009

Narehan Hassan is with the Universiti Teknologi MARA, 42300 Puncak Alam, Selangor.

Syahrina Hayati Md. Jani is now with the Universiti Teknologi MARA (Perak), Kampus Seri Iskandar, Bandar Seri Iskandar, 32610 Bandar Seri Iskandar, Perak. 